\title{
Feeding high proportions of barley grain in a total mixed ration perturbs diurnal patterns of plasma metabolites in lactating dairy cows
}

\author{
B. N. Ametaj, ${ }^{1}$ D. G. V. Emmanuel, ${ }^{2}$ Q. Zebeli, and S. M. Dunn \\ Department of Agricultural, Food and Nutritional Science, University of Alberta, Edmonton, Alberta, Canada T6G 2P5
}

\begin{abstract}
The aim of this study was to evaluate effects of feeding increasing proportions of barley grain in a total mixed ration (TMR) on diurnal plasma metabolite fluctuations in high-producing dairy cows. Eight earlyto mid-lactation (60 to $140 \mathrm{~d}$ in milk) primiparous Holstein cows were assigned to a double $4 \times 4$ Latin square experimental design. Each experimental period lasted $21 \mathrm{~d}$ with the first $11 \mathrm{~d}$ used for diet adaptation. Cows were fed a TMR once daily at $0800 \mathrm{~h}$ containing no barley grain (control diet), or 15, 30, and $45 \%$ (dry matter basis) barley grain as well as barley silage. Blood samples were collected from the tail vein on the last day of each period shortly before (i.e., 0 h) and at 2, 4, 6, 8, 10, and $12 \mathrm{~h}$ after the morning feeding. Concentrations of glucose, nonesterified fatty acids (NEFA), $\beta$-hydroxybutyric acid, cholesterol, and lactate in plasma were measured. Results of this study showed that feeding increasing proportions of barley grain affected concentrations of glucose and lactate in plasma with greater plasma glucose and lactate in cows fed the highest amount of grain; however, the amount of grain in the diet did not have an effect on diurnal patterns of plasma glucose. Additionally, the concentration of NEFA in plasma was greater in cows fed the higher grain diets and was greater in the hours following the morning meal than later in the day. The amount of grain in the diet was associated with lower plasma $\beta$-hydroxybutyric acid, which increased particularly after the morning meal. Interestingly, cows fed the most barley grain had the lowest plasma cholesterol and this decreased during the day. In conclusion, the concomitant increase of glucose, lactate, and NEFA as well as the decrease of plasma cholesterol in cows fed high proportions of barley grain suggest that high inclusion of barley grain in the diet played a role in the diurnal patterns of plasma metabolites in lactating
\end{abstract}

Received June 18, 2008.

Accepted November 1, 2008.

${ }^{1}$ Corresponding author: burim.ametaj@ualberta.ca

${ }^{2}$ Current address: Department of Pharmaceutical Sciences, University of Toronto, Toronto, Ontario, Canada M5S 3M2. dairy cows. However, further research is warranted to understand involvement of these metabolic changes on the long-term health and productivity of dairy cows. Key words: barley grain, dairy cow, diurnal, metabolic response

\section{INTRODUCTION}

Lactating dairy cows require large amounts of dietary energy to meet requirements for maintenance, milk production, and reproduction. To support the high energetic and nutrient demands, lactating dairy cattle are typically fed diets high in cereal grains as a highly digestible energy source. However, feeding diets high in readily fermentable carbohydrates increases the odds of developing subacute ruminal acidosis and decreases the long-term productive performance of dairy cows (Stone, 2004; Zebeli et al., 2008a). In addition, numerous studies have recently demonstrated that feeding cattle diets rich in highly degradable carbohydrates results in disorders such as acidosis, fatty liver, laminitis, liver abscesses, displaced abomasum, and bloat (Nocek, 1997; Andersen, 2003; Ametaj et al., 2005).

Although the exact mechanism(s) underlying the relationship between feeding large amounts of cereal grains and the high incidence of metabolic diseases is not yet completely understood, research has described several events associated with feeding high-grain diets. For example, digestion of increasing amounts of cereal grains was shown to initiate major changes in the composition of microbiota in favor of gram-negative bacteria (Dunlop, 1972; Mackie et al., 1978). Additionally, other researchers found that bacterial alterations were associated with the release of large amounts of endotoxin, a cell-wall component of all gram-negative bacteria, in the rumen fluid (Nagaraja et al., 1978; Andersen et al., 1994; Emmanuel et al., 2008). Interestingly, translocation of endotoxin into the circulatory system has been implicated to be associated with multiple perturbations of different plasma metabolites (Dougherty, 1976; Ametaj et al., 2005; Nagaraja and Lechtenberg, 2007). In fact, plasma metabolites are frequently used to monitor the metabolic health status of dairy herds. However, most of the available data describing the 
metabolic and productive responses of lactating dairy cows to the grain level in the diet are based on a few measurements obtained over a large interval of time, such as days or weeks or longer. In addition, there is no information on the role that barley grain fed as TMR plays on diurnal perturbations of blood metabolites in dairy cows around the peak of lactation. Because diurnal variations are more related to feed intake patterns, we hypothesized that the diurnal patterns of the plasma metabolites may better express the metabolic responses of dairy cows to increasing proportions of barley grain.

Therefore, the objective of the present investigation was to study the effects of feeding increasing proportions of barley grain at $0,15,30$, and $45 \%$ of the ration DM as a TMR on the diurnal responses of plasma glucose, NEFA, BHBA, cholesterol, and lactate in dairy cows transitioning from early- to mid-lactation. Results related to feed intake and acute phase response data were evaluated and published in a companion article (Emmanuel et al., 2008).

\section{MATERIALS AND METHODS}

\section{Animals and Diets}

Eight ruminally cannulated (100 mm diameter, Bar Diamond, Parma, ID) primiparous Holstein cows were used in a double $4 \times 4$ Latin square design. The experimental period was $21 \mathrm{~d}$ with $11 \mathrm{~d}$ as adaptation period and the remaining $10 \mathrm{~d}$ as the measurement period. At the start of the experiment, the cows were at (mean $\pm \mathrm{SD}) 60 \pm 15 \mathrm{~d}$ postpartum. All cows were fed the same basic ration supplemented with barley grain at 0 , 15,30 , or $45 \%$ and barley silage at $58,43,28$, or $13 \%$, providing 4 different NFC levels at 35.4, 38.8, 42.1, and $45.5 \%$ (DM basis), respectively. The amount of grain in the diet was stepped up or down during the adaptation period. All experimental procedures were approved by the University of Alberta Animal Policy and Welfare Committee, and animals were cared for in accordance with the guidelines of the Canadian Council on Animal Care (1993). The cows were housed in tie stalls with free access to water at all times, fed once daily at $0800 \mathrm{~h}$, and milked twice daily at 0500 and $1600 \mathrm{~h}$. Daily ration was offered as a TMR for ad libitum intake to allow about $5 \%$ feed refusals. The DM content of barley silage, alfalfa silage, and alfalfa hay was determined every $2 \mathrm{wk}$ to adjust the allocation of forages and to maintain the predetermined forage-to-concentrate ratio on a DM basis in the TMR. Diet ingredients were analyzed for concentrations of DM, ash, NDF, and ether extract. The DM concentration was determined by drying samples at $135^{\circ} \mathrm{C}$ for $2 \mathrm{~h}(\mathrm{AOAC}, 1990)$. Ash concentration was determined after $5 \mathrm{~h}$ at $500^{\circ} \mathrm{C}$ in a furnace. Methods of
Van Soest et al. (1991) were used in analyses of NDF and ADF using heat-stable amylase and sodium sulfite in the case of NDF. Diets were formulated to meet or exceed the nutrient requirements of a $680-\mathrm{kg}$ lactating cow according to NRC (2001) guidelines. Estimated CP and ME contents were similar across the different diets. Ingredients and nutrient composition of the TMR are presented in Table 1.

\section{Sample Collection}

Blood samples were collected from coccygeal vein on $\mathrm{d} 10$ of the experimental period every $2 \mathrm{~h}$ starting from 0800 until 2000 h using 10-mL Vacutainer tubes (Becton Dickinson, Franklin Lake, NJ) containing sodium heparin anticoagulant. Blood samples were stored in ice and centrifuged (Rotanta $460 \mathrm{R}$, Hettich Zentrifugan, Tuttlingen, Germany) within 20 min at 3,000 $\times g$ and $4^{\circ} \mathrm{C}$ for $20 \mathrm{~min}$ to separate plasma. Plasma samples were stored at $-20^{\circ} \mathrm{C}$ until analysis.

\section{Sample Analyses}

Concentration of glucose in plasma was quantified by an enzymatic method by using a commercially available kit (Diagnostic Chemicals Ltd., Charlottetown, Prince Edward Island, Canada). Briefly, the procedure involves phosphorylation and oxidization of glucose in samples resulting in the production of $\mathrm{NADH}$, which produces a color proportional to the glucose concentration in the sample. All samples were tested in duplicate and the plasma glucose was then determined by reading on a microplate spectrophotometer (Spectramax 190, Molecular Devices Corp., Sunnyvale, CA) at an optical density of $340 \mathrm{~nm}$. According to the manufacture's instructions, the lower limit of detection of the test was $0.06 \mathrm{mg} / \mathrm{dL}$.

Quantitative determination of plasma NEFA was done by using an enzymatic colorimetric method using a commercially available kit (Wako Chemicals, Richmond, VA). The test involves acylation of coenzyme A by fatty acids in the sample in presence of acyl-CoA synthetase and production of hydrogen peroxide in presence of acyl-CoA oxidase. Hydrogen peroxide, in presence of peroxidase, permits the oxidative condensation of 3-methyl-N-ethyl-N- $\beta$-hydroxy ethyl-O-aniline (MEHA) with 4-aminoantipyrine to form a purple adduct, which is proportional to the concentration of NEFA in the sample. Samples were tested in duplicate and the optical density was measured at $550 \mathrm{~nm}$ on a microplate spectrophotometer (Spectramax 190, Molecular Devices Corp.). The lower limit of detection of the assay was $0.50 \mathrm{mEq} / \mathrm{L}$. 
Table 1. Ingredients and nutrient composition of the 4 experimental TMR differing in the level of barley inclusion

\begin{tabular}{|c|c|c|c|c|}
\hline Item & \multicolumn{4}{|c|}{ Barley, \% } \\
\hline \multicolumn{5}{|l|}{ Ingredient, $\%$ of DM } \\
\hline Alfalfa silage & 12.00 & 12.00 & 12.00 & 12.00 \\
\hline Barley silage & 58.00 & 43.00 & 28.00 & 13.00 \\
\hline Rolled barley & 0.00 & 15.00 & 30.00 & 45.00 \\
\hline Dairy premix ${ }^{1}$ & 0.58 & 0.58 & 0.58 & 0.58 \\
\hline Megalac ${ }^{2}$ & 1.79 & 1.79 & 1.79 & 1.79 \\
\hline Limestone & 0.58 & 0.58 & 0.58 & 0.58 \\
\hline Biofos $^{3}$ & 0.40 & 0.40 & 0.40 & 0.40 \\
\hline Magnesium oxide & 0.35 & 0.35 & 0.35 & 0.35 \\
\hline Sodium bicarbonate & 0.76 & 0.76 & 0.76 & 0.76 \\
\hline $\mathrm{ME}, \mathrm{Mcal} / \mathrm{kg}$ of DM & 2.45 & 2.42 & 2.40 & 2.39 \\
\hline $\mathrm{CP}$ & 16.2 & 16.4 & 16.5 & 16.7 \\
\hline $\mathrm{NDF}$ & 32.8 & 30.2 & 27.6 & 25.0 \\
\hline $\mathrm{ADF}$ & 21.8 & 19.4 & 17.0 & 14.6 \\
\hline $\mathrm{NFC}^{6}$ & 35.4 & $\begin{array}{l}19.4 \\
38.8\end{array}$ & 42.1 & 45.5 \\
\hline $\mathrm{Ca}$ & 1.30 & 1.30 & 1.20 & 1.20 \\
\hline $\mathrm{P}$ & 0.40 & 0.40 & 0.50 & 0.50 \\
\hline $\mathrm{DCAD}, \mathrm{mEQ} / \mathrm{kg}$ & 300 & 274 & 248 & 223 \\
\hline
\end{tabular}

${ }^{1}$ Contained calcium $0.1 \%$, phosphorous $0.6 \%$, sodium $11.5 \%$, magnesium $0.3 \%$, potassium $0.7 \%$, sulfur $0.23 \%$, zinc $5,000 \mathrm{mg} / \mathrm{kg}$, copper 1,170 $\mathrm{mg} / \mathrm{kg}$, manganese $3,100 \mathrm{mg} / \mathrm{kg}$, iodine $80 \mathrm{mg} / \mathrm{kg}$, cobalt $6.2 \mathrm{mg} / \mathrm{kg}$, vitamin A 1,265,000 IU/ kg, vitamin D 142,000 IU/kg, vitamin E 3,800 $\mathrm{IU} / \mathrm{kg}$.

${ }^{2}$ Contained $85 \%$ fat as fatty acids and $9.6 \%$ calcium with a $\mathrm{NE}_{\mathrm{L}}$ of $6.52 \mathrm{Mcal} / \mathrm{kg}$ (Champion Feed Services Ltd., Barrhead, Alberta, Canada).

${ }^{3}$ Contained monocalcium phosphate and dicalcium phosphate in the ratio 2:1 (Champion Feed Services Ltd.).

${ }^{4}$ Contained 5,000 IU $/ \mathrm{kg}$.

${ }^{5}$ Contained 500,000 IU $/ \mathrm{kg}$.

${ }^{6} \mathrm{NFC}=100-(\%$ ash $+\% \mathrm{CP}+\% \mathrm{NDF}+\%$ ether extracts $)$.

Enzymatic quantitation of BHBA by $\beta$-hydroxybutyrate dehydrogenase was used to quantify plasma concentration of BHBA using a commercially available kit (Stanbio Laboratory, Boerne, TX). The test involves conversion of BHBA to acetoacetate and NADH at $\mathrm{pH} 8.5$ by $\beta$-hydroxybutyrate dehydrogenase in the presence of NAD. The NADH produced reacts with 2-p-iodophenyl-3-p-nitrophenyl-5-phenyltetrazolium chloride (INT) in the presence of diaphorase to produce a color proportional to the concentration of BHBA in the sample. Plasma BHBA was measured in duplicate by reading on a microplate spectrophotometer (Spectramax 190, Molecular Devices Corp.) at an optical density of $505 \mathrm{~nm}$. The lower limit of detection of the assay was $0.125 \mu \mathrm{mol} / \mathrm{mL}$.

Plasma cholesterol was measured using a commercially available kit (Diagnostic Chemicals Ltd.). The colorimetric method is based on the principle of hydrolyzing the cholesterol esters to free cholesterol and oxidation of free cholesterol to cholest-4ene-3-one with simultaneous production of hydrogen peroxide. The hydrogen peroxide couples with 4-aminoantyrine and p-hydroxybenzoate in the presence of peroxidase to yield a chromogen, the intensity of which is proportional to concentration of cholesterol in the sample. All samples were tested in duplicate and plasma cholesterol was determined by reading the optical density values on a microplate spectrophotometer (Spectramax 190, Molecular Devices Corp.) at $505 \mathrm{~nm}$.

Plasma concentration of lactate was determined using a commercially available lactate assay kit (Biomedical Research Service Center, Buffalo, NY). The test involves reduction of tetrazolium salt INT in a NADHcoupled enzymatic reaction to formazan, which exhibits a red color, the intensity of which is proportional to the concentration of lactate. The lactate standard provided in the kit was diluted to set a detection range of 125 to $1,000 \mu M$. All samples were tested in duplicate and 


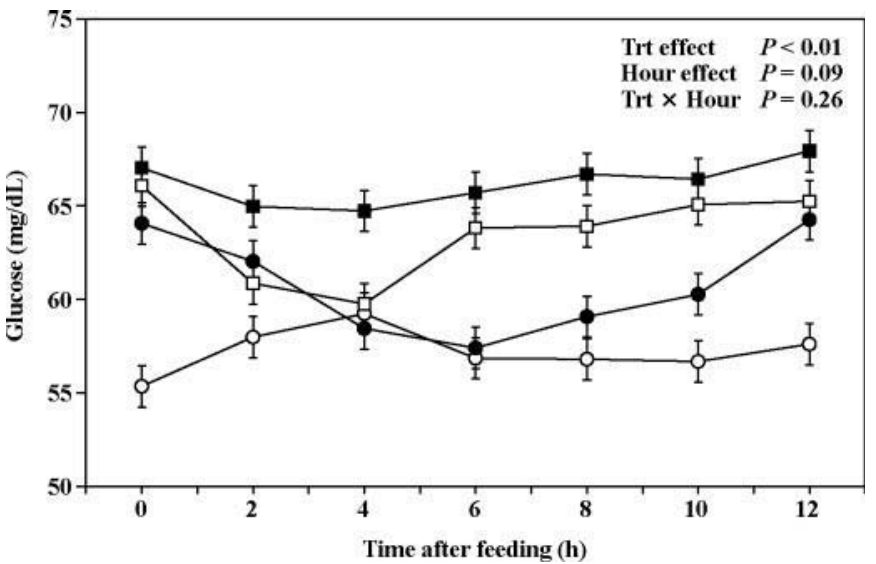

Figure 1. Least squares means $( \pm \mathrm{SEM})$ of plasma glucose in Holstein dairy cows (60 to 140 DIM; $\mathrm{n}=8$ ) fed increasing proportions of grain at $0(\bigcirc), 15(\bullet), 30(\square)$, or $45 \%(\mathbf{\square})$ barley grain in the diet (DM basis).

the lactate concentration was determined by reading the optical density values on a microplate spectrophotometer (Spectramax 190, Molecular Devices Corp.) at $492 \mathrm{~nm}$.

\section{Statistical Analyses}

All data were analyzed using the MIXED procedure (SAS Institute Inc., Cary, NC; version 9.1.3) according to the model shown below:

$$
Y_{\mathrm{ijk}}=\mu+\alpha_{i}+\beta_{j}+(\alpha \beta)_{i j}+e_{i j k},
$$

where $Y_{i j k}$ is the observations for dependent variables, $\mu$ is the population mean, $\alpha_{i}$ is a population parameter corresponding to treatment $i, \beta_{j}$ is the fixed effect of measurement hour $j,(\alpha \beta)_{i j}$ is the effect of treatment by time interaction, and $e_{i j k}$ is the residual error. The measurements at different hours in the same cow were considered as repeated measures in the model. The covariance structure of the repeated measures for each response variable was modeled separately according to the smallest values of the fit statistics based on the Bayesian information criteria and an appropriate structure fitted. The PDIFF option was used in each of the comparisons. To test linear or quadratic effects of treatment on all response parameters, the orthogonal contrasts with CONTRAST statement of SAS (SAS Institute Inc.) were used. Significance was declared at $P \leq 0.05$.

\section{RESULTS}

In this study, cows increased feed intake and milk production with increasing barley grain in the diet.
For example, during the last $10 \mathrm{~d}$ of the experimental period, cows consumed on average 13.3, 15.3, 14.7, and $16.0 \mathrm{~kg}$ of $\mathrm{DM} / \mathrm{d}(\mathrm{SEM}= \pm 0.63 ; P<0.01)$ and produced $27.2,28.2,29.0$, and $31.1 \mathrm{~kg}$ of milk/d $(\mathrm{SEM}=$ $\pm 1.24 ; P<0.01)$ when they were fed diets based on 0 , 15,30 , and $45 \%$ barley grain, respectively.

Results of glucose concentration in the plasma measured at different times after the morning feeding are given in Figure 1. Plasma glucose was linearly increased with the increasing grain proportion in the $\operatorname{diet}(P<$ 0.01 ) such that the group of cows fed $45 \%$ grain had the greatest concentration of glucose. In contrast, the factor time of feeding alone or in combination with the dietary treatment did not show an effect on diurnal plasma glucose $(P>0.05)$ in the present study.

Data of diurnal concentrations of plasma NEFA are given in Figure 2. The ANOVA revealed an interaction between barley grain proportion in the diet and measurement time $(P<0.01)$. Thus, for cows fed no barley grain, NEFA concentration was greatest only during the first hours after the morning feeding; however, starting at $4 \mathrm{~h}$ after the feeding, the concentration of plasma NEFA in this group was lower compared with cows fed $45 \%$ grain. Dietary treatment had a quadratic effect on overall NEFA $(P<0.01)$ with concentrations averaging $152.7,102.2,113.1$, and $151.2 \mu \mathrm{Eq} / \mathrm{L}$ for diets having $0,15,30$, and $45 \%$ barley grain, respectively. In addition, the factor time of feeding affected plasma NEFA early after the feeding in cows fed the highest grain proportions and declined during the day in all treatment groups, reaching the lowest value $10 \mathrm{~h}$ after the morning feeding.

Results of the ANOVA for concentration of BHBA in plasma are shown in Figure 3. Feeding increasing

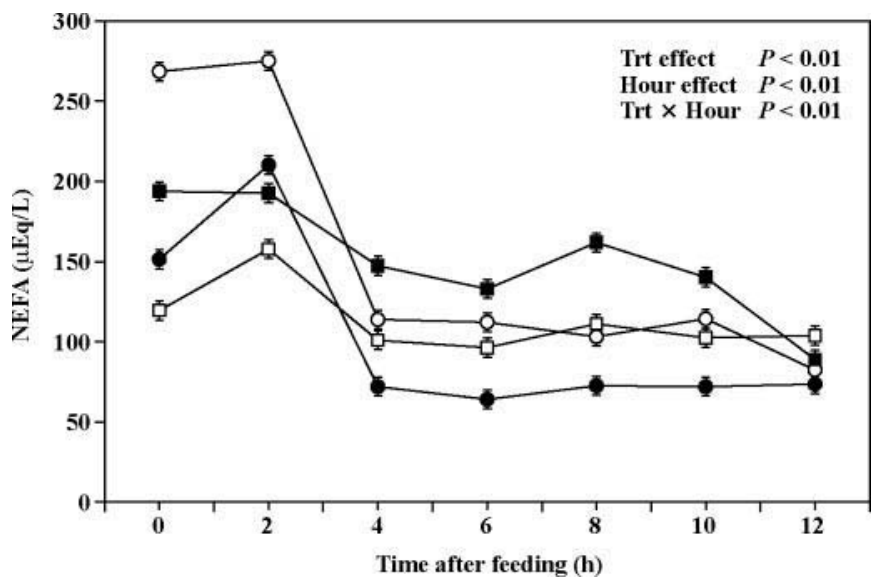

Figure 2. Least squares means $( \pm \mathrm{SEM})$ of plasma NEFA in Holstein dairy cows (60 to 140 DIM; $\mathrm{n}=8$ ) fed increasing proportions of grain at $0(\bigcirc), 15(\bullet), 30(\square)$, or $45 \%$ ( $)$ barley grain in the diet (DM basis). 


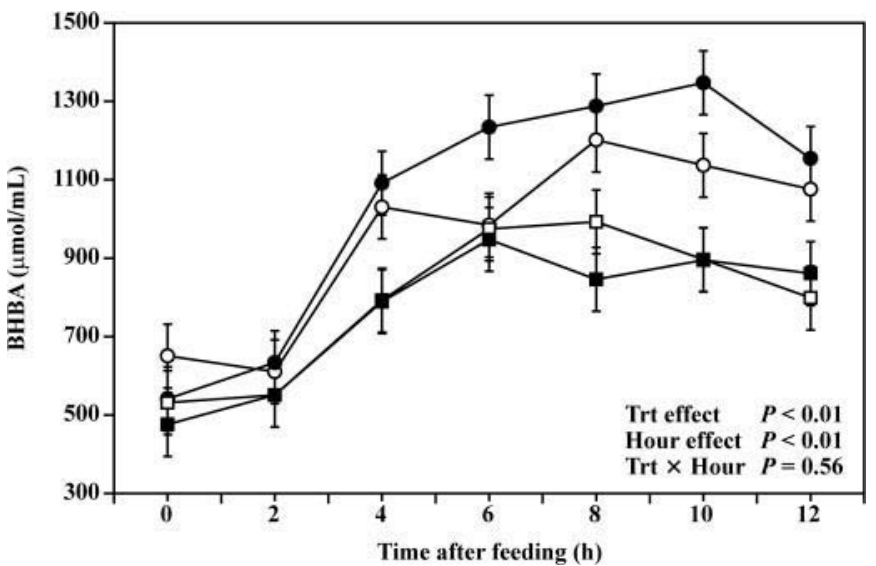

Figure 3. Least squares means $( \pm \mathrm{SEM})$ of plasma BHBA in Holstein dairy cows (60 to $140 \mathrm{DIM} ; \mathrm{n}=8$ ) fed increasing proportions of grain at $0(\bigcirc), 15(\bullet), 30(\square)$, or $45 \%$ ( $)$ barley grain in the diet (DM basis).

amounts of barley grain linearly decreased concentrations of BHBA in plasma $(P<0.01)$. Also, time after feeding affected plasma concentrations of BHBA $(P<$ 0.01). In general, the concentration of BHBA increased $4 \mathrm{~h}$ after the morning feeding achieving a quasi-asymptotic plateau that lasted until $10 \mathrm{~h}$ after feeding in almost all treatment groups $(P<0.01)$. No effect was obtained for the interaction between treatment and time after feeding (Figure 3).

Increasing the amount of barley grain in the diet linearly increased the concentration of lactate in plasma $(P<0.01 ;$ Figure 4$)$. The group of cows fed $45 \%$ grain had the greatest diurnal plasma lactate concentrations, whereas the control group had the lowest concentrations of plasma lactate. The other 2 groups (fed 15

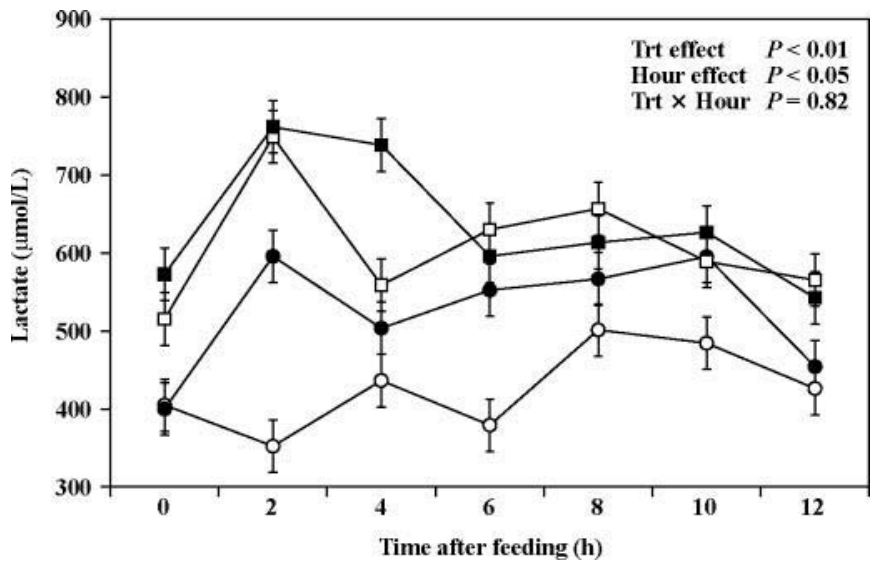

Figure 4. Least squares means $( \pm$ SEM) of plasma lactate in Holstein dairy cows (60 to 140 DIM; $\mathrm{n}=8$ ) fed increasing proportions of grain at $0(\bigcirc), 15(\bullet), 30(\square)$, or $45 \%$ ( $)$ barley grain in the diet (DM basis). and $30 \%$ barley grain) had intermediate concentrations of plasma lactate between the control group and the group fed $45 \%$ barley grain. In addition, time after feeding affected concentration of lactate in plasma in this study $(P<0.05$; Figure 4$)$.

Feeding different amounts of grain influenced diurnal concentrations of cholesterol both linearly $(P<$ 0.01 ; Figure 5) and quadratically $(P=0.04)$. Overall, plasma cholesterol was lowest in the group fed $45 \%$ grain $(292 \mathrm{mmol} / \mathrm{L})$ and highest in the control group $(335 \mathrm{mmol} / \mathrm{L})$. In addition, plasma cholesterol was affected by the time after feeding $(P<0.01)$ and by the interaction between treatment and time after feeding $(P<0.01 ;$ Figure 5).

\section{DISCUSSION}

Our finding that glucose concentrations in plasma remained unchanged throughout the daytime suggests that the amount of barley grain in the diet had no influence on diurnal fluctuations of plasma glucose. Interestingly, our data are in contrast with previous research work (Blum et al., 1985; Borrebaek et al., 1990) that reported variations in diurnal patterns of plasma glucose in dairy cows fed different amounts of concentrate twice a day and not as part of a TMR. The discrepancy of the present results with the aforementioned studies might be because of differences in the feeding procedure (i.e., ingredients fed separately vs. TMR diet) as well as differences in meal frequency (i.e., 2 or 4 times per day vs. once daily in our study). On the other hand, our results agree with research conducted by Nielsen et al. (2003) who also demonstrated unchanged diurnal plasma glucose concentrations when dairy cows were

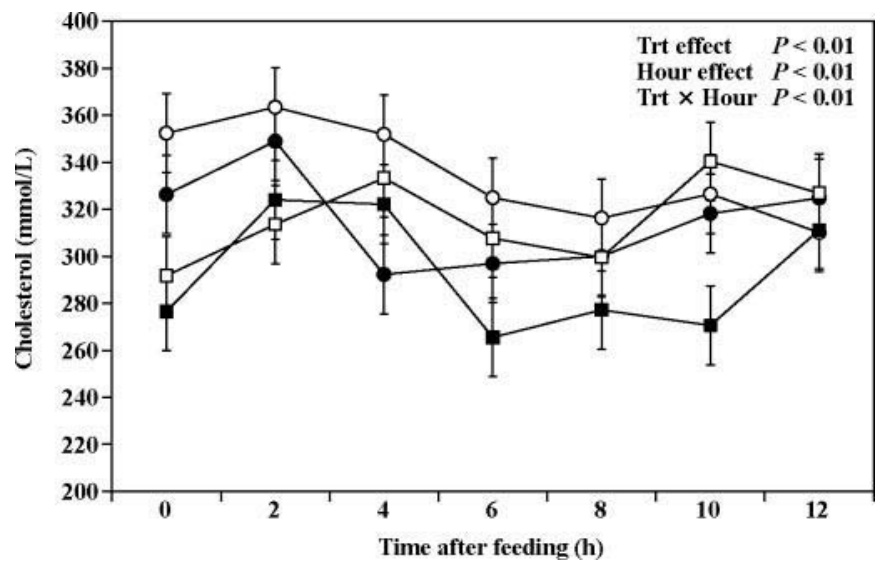

Figure 5. Least squares means $( \pm \mathrm{SEM})$ of plasma cholesterol in Holstein dairy cows (60 to 140 DIM; $\mathrm{n}=8$ ) fed increasing proportions of grain at $0(\bigcirc), 15(\bullet), 30(\square)$, or $45 \%(\square)$ barley grain in the diet (DM basis). 
fed a TMR with 2 different proportions of concentrate once daily. Thus, these observations indicate that the feeding procedure should be taken into consideration when evaluating diurnal patterns of plasma glucose in dairy cows.

Another interesting observation of this study was that cows fed barley grain at $45 \%$ of DM had greater concentrations of glucose compared with the other experimental groups. The greater plasma concentrations of glucose in cows fed higher proportions of grain can be explained by enhanced production and absorption of propionate in the rumen as well as its conversion to glucose in the liver through the process of hepatic glucogenesis (Reynolds, 2006). Indeed, results of this study indicated that increasing the amount of barley grain from 0 to 15,30 , and $45 \%$ in the diet increased the concentration of propionate in the rumen fluid from 16.9 to $20.6,20.5$, and $30.7 \mathrm{mmol} / \mathrm{L}$, respectively.

Data from this study showed that peak concentrations of plasma NEFA occurred immediately after the morning feeding, particularly in cows fed a low-grain or no-grain diet. This finding is in accordance with previous reports (Blum et al., 1985; Nielsen et al., 2003; Guo et al., 2007) and suggests that sampling time is important when using plasma NEFA as an indicator of energy status in dairy cows. Greater plasma NEFA obtained early after the morning feeding in this study can be explained by lower DMI of dairy cows during the night hours (Zebeli et al., 2008b). Release of NEFA in plasma is determined predominantly by their mobilization from adipose tissue triacylglycerol stores through the process of lipolysis in response to variations in the energy demand of the animal (Pullen et al., 1989). The liver oxidizes NEFA to ketone bodies and carbon dioxide via the tricarboxylic acid cycle or esterifies them to triacylglycerol, which are exported from the liver as very low density lipoproteins (Rukkwamsuk et al., 1998). If these processes become too dramatic, they can lead to development of ketosis or fatty liver.

Interestingly, our observation that cows fed the greatest proportion of barley grain (i.e., 45\%) had the greatest concentrations of circulating NEFA during most of the day does not fully support the hypothesis that the release of NEFA in plasma (i.e., lipolysis) is associated with the lack of energy. Other results of this study also demonstrated that the availability of glucose and DMI were greatest in the group of cows fed $45 \%$ grain. Similarly, Nielsen et al. (2003) reported greater plasma NEFA, during several hours of the day, in cows fed a TMR based on a concentrate mixture consisting of rolled wheat and sugar beet (at approximately 30 and $21 \%$, respectively, DM basis) compared with cows fed no grain in the diet. Moreover, recent research conducted by Guo et al. (2007) demonstrated that a high feeding level was not able to modulate the magnitude of postpartum NEFA increase in dairy cows.

The observations obtained in the present study and in other reports suggest that part of the increase in plasma NEFA might be related to adverse effects of feeding high proportions of barley grain in the diet. In fact, the latter factor seems to overpower any possible effects of deficient energy on circulating plasma NEFA. Previously, we showed that the amount of endotoxin in the rumen fluid increased 8- to 14-fold during feeding of 30 and $45 \%$ barley grain, respectively (Emmanuel et al., 2008). Cows fed greater amounts of grain also showed signs of inflammation with enhanced plasma acute phase proteins such as serum amyloid A, LPS-binding protein, and C-reactive protein in plasma (Emmanuel et al., 2008). Accordingly, research conducted by Steiger et al. (1999) demonstrated that there is a stimulation of lipolysis during the initial phase of endotoxin administration in heifers reflected by an increase of NEFA and glycerol in the plasma. Enhanced concentrations of adrenocorticotropic hormone, cortisol, and catecholamine as well as enhanced activity of the sympathetic nervous system contribute to the lipolytic response to the endotoxin challenge (Boosman et al., 1990; Nonogaki and Iguchi, 1997). In addition, a decrease in the utilization of NEFA by muscle tissue is reported to contribute to the endotoxin-induced increase of plasma NEFA (Romanowsky et al., 1980). Besides its effects on plasma NEFA, endotoxin also induces changes in carbohydrate metabolism that are attributed to the secretion of adrenocorticotropic hormone, cortisol, and activation of the sympathetic nervous system (Boosman et al., 1990; Nonogaki and Iguchi, 1997). Additionally, the interaction of macrophages and endotoxin produces cytokines such as IL-1, which has been shown to increase concentration of glucagon in plasma that in turn increases the concentration of glucose by glucolysis (Zenser and Powanda, 1977).

Thus, the concomitant increase of glucose and NEFA in plasma of cows fed high proportions of barley grain suggests that the high level of barley grain in the diet perturbed plasma metabolites by inducing a systemic inflammatory response. Interestingly, this postulate is supported by results of the circulating diurnal cholesterol and lactate concentrations in plasma. This investigation demonstrated that plasma cholesterol decreased with increasing proportions of barley grain in the diet. Research conducted by Chiarla et al. (2004) reported that hypocholesterolemia is among the biochemical abnormalities characterizing the severity of the acute phase response. Interestingly, in the aforementioned study, a low plasma cholesterol concentration and high level of C-reactive protein were associated with increased levels of plasma lactate as well as changes in 
the patterns of some plasma amino acids, indicating that the disturbances of plasma metabolites may be interrelated because of the action of the same causal agent. Indeed, we also reported a greater concentration of plasma lactate throughout the day with increasing the proportions of grain in the diet. Greater production and subsequent absorption of lactate through rumen wall because of higher intake of starch for cows fed high-grain diets could partly explain this metabolic event. However, it is well accepted that the odds for lactate accumulation in the rumen of dairy cows are typically low because lactate is quickly converted to propionate via acrylate (Stone, 2004). Therefore, the greater level of plasma lactate observed in the present study might be discussed as the whole metabolic response of the cows to the high proportions of grain and its associative effects on rumen metabolism, endotoxin release, and resulting activation of a systemic inflammatory response (Emmanuel et al., 2008). For example, Steiger et al. (1999) discussed enhanced glycogenolysis and reduced capacity of extrahepatic tissues to utilize lactate as major contributors to the approximately $50 \%$ increase in plasma lactate in response to endotoxin challenge in heifers.

The patterns of plasma BHBA during the day showed the reverse trend compared with those of plasma NEFA. Thus, concentrations of BHBA in plasma were lowest early after the morning feeding and increased at about $4 \mathrm{~h}$ after the meal. This may be explained partly by the fact that BHBA is produced in hepatocytes as well as in rumen epithelial cells (Heitmann and Fernandez, 1986). So, when plasma NEFA is high in the morning hours, hepatic production of BHBA may compensate for the relatively low production of BHBA by rumen epithelial cells related to low feed intake during the night and morning hours.

In the present study, cows fed greater proportions of barley grain had lower plasma concentrations of BHBA. There are 2 sources of BHBA in ruminants. First, plasma BHBA comes from oxidation of NEFA in liver hepatocytes during conditions associated with high levels of circulating glucose and insulin (Roche et al., 2008). Second, the butyrate in silage is another source of BHBA for ruminant animals. For example, Andersson and Lundström (1985) found a positive correlation between butyrate intakes from silage and ketone bodies in plasma. In our study, the TMR of cows fed 0 and $15 \%$ barley grain also had 70 and $55 \%$ barley/alfalfa silage, respectively, on a DM basis. The increased amount of silage might have contributed in part to the increased plasma concentrations of BHBA in the no-grain and low-grain groups.

In conclusion, the results of this study suggest that diurnal patterns of NEFA, BHBA, cholesterol, and lac- tate should be considered when investigating effects of grain level on metabolic health in dairy cows. The concomitant increase of glucose, lactate, and NEFA as well as the decrease of plasma cholesterol in cows fed high proportions of barley grain suggest that the high proportion of barley grain played a role in the metabolite disturbances in dairy cows transitioning from early- to mid-lactation. Therefore, further research is warranted to understand the contribution of these metabolic changes on the long-term health and productivity of dairy cows.

\section{ACKNOWLEDGMENTS}

We acknowledge the financial support of Alberta Milk (Edmonton, Alberta, Canada), Alberta Funding Consortium (Edmonton, Alberta, Canada), and Natural Sciences and Engineering Research Council of Canada (Ottawa, Ontario, Canada). We thank R. Periasamy Pandian, S. Sivaraman, and R. Psutka for helping with the sampling and laboratory analyses. We are grateful to the technical staff at Dairy Research and Technology Center, University of Alberta, for their help with and care of the cows. We thank Laki Goonewardene for statistical advice.

\section{REFERENCES}

Ametaj, B. N., B. J. Bradford, G. Bobe, R. A. Nafikov, Y. Lu, J. W. Young, and D. C. Beitz. 2005. Strong relationships between mediators of the acute phase response and fatty liver in dairy cows. Can. J. Anim. Sci. 85:165-175.

Andersen, P. H. 2003. Bovine endotoxicosis: Some aspects of relevance to production diseases. Acta Vet. Scand. 8(Suppl.):141-155.

Andersen, P. H., B. Bergelin, and K. A. Christensen. 1994. Effect of feeding regimen on concentration of free endotoxin in ruminal fluid of cattle. J. Anim. Sci. 72:487-491.

Andersson, L., and K. Lundström. 1985. Effect of feeding silage with high butyric acid content on ketone body formation and milk yield in postparturient dairy cows. Zbl. Vet. Med. A 32:15-23.

AOAC. 1990. Official Methods of Analysis. 15th ed. Association of Official Analytical Chemists, Washington, DC.

Blum, J. W., F. Jans, F. Moses, D. Froehli, M. Zemp, M. Wanner, I. C. Hart, R. Thun, and U. Keller. 1985. Twenty four-hour pattern of blood hormone and metabolite concentrations in high-yielding dairy cows: Effects of feeding low or high amounts of starch or crystalline fat. Zbl. Vet. Med. A 32:401-418.

Boosman, R., C. W. Mutsaers, and A. Klarenbeek. 1990. Sympathicoadrenal effects of endotoxaemia in cattle. Vet. Rec. 127:11-14.

Borrebaek, B., K. Halse, B. Tveit, H. K. Dahle, and L. Ceh. 1990. Plasma glucose, ketone bodies, insulin, glucagon and enteroglucagon in cows: Diurnal variations related to ketone levels before feeding and to the ketogenic effects of feeds. Acta Vet. Scand. 31:5-15.

Canadian Council on Animal Care. 1993. Guide to the Care and Use of Experimental Animals. Vol. 1. 2nd ed. CCAC, Ottawa, Ontario, Canada.

Chiarla, C., I. Giovannini, and J. H. Siegel. 2004. The relationship between plasma cholesterol, amino acids and acute phase proteins in sepsis. Amino Acids 27:97-100.

Dougherty, R. W. 1976. Problems associated with feeding farm livestock under intensive systems. World Rev. Nutr. Diet. 25:249-275.

Dunlop, R. H. 1972. Pathogenesis of ruminant lactic acidosis. Adv. Vet. Sci. Comp. Med. 16:259-302. 
Emmanuel, D. G., S. M. Dunn, and B. N. Ametaj. 2008. Feeding high proportions of barley grain stimulates an inflammatory response in dairy cows. J. Dairy Sci. 91:606-614.

Guo, J., R. R. Peters, and R. A. Kohn. 2007. Effect of a transition diet on production performance and metabolism in periparturient dairy cows. J. Dairy Sci. 90:5247-5258.

Heitmann, R. N., and J. M. Fernandez. 1986. Autoregulation of alimentary and hepatic ketogenesis in sheep. J. Dairy Sci. 69:1270-1281.

Mackie, R. I., F. M. C. Gilchrist, A. M. Roberts, P. E. Hannah, and H. M. Schwartz. 1978. Microbiological and chemical changes in the rumen during the stepwise adaptation of sheep to high concentrate diets. J. Agric. Sci. 90:241-254.

Nagaraja, T. G., E. E. Bartley, L. R. Fina, and H. D. Anthony. 1978. Relationship of rumen gram-negative bacteria and free endotoxin to lactic acidosis in cattle. J. Anim. Sci. 47:1329-1336.

Nagaraja, T. G., and K. F. Lechtenberg. 2007. Acidosis in feedlot cattle. Vet. Clin. North Am. Food Anim. Pract. 23:333-350.

Nielsen, N. I., K. L. Ingvartsen, and T. Larsen. 2003. Diurnal variation and the effect of feed restriction on plasma and milk metabolites in TMR-fed dairy cows. J. Vet. Med. A 50:88-97.

Nocek, J. E. 1997. Bovine acidosis: Implications on laminitis. J. Dairy Sci. 80:1005-1028.

Nonogaki, K., and A. Iguchi. 1997. Stress, acute hyperglycemia and hyperlipidemia-role of the autonomic nervous system and cytokines. Trends Endocrinol. Metab. 8:192-197.

NRC. 2001. Nutrient Requirements of Dairy Cattle. 7th rev. ed. Natl. Acad. Sci., Washington, DC.

Pullen, D. L., D. L. Palmquist, and R. S. Emery. 1989. Effect of days of lactation and methionine hydroxy analog on incorporation of plasma fatty acids into plasma triglycerides. J. Dairy Sci. 72:4958.

Reynolds, C. K. 2006. Production and metabolic effects of site of starch digestion in dairy cattle. Anim. Feed Sci. Technol. 130:78-94.
Roche, J. R., A. J. Sheahan, L. M. Chagas, and R. C. Boston. 2008. Short communication: Change in plasma ghrelin in dairy cows following an intravenous glucose challenge. J. Dairy Sci. 91:10051010.

Romanowsky, A. J., G. J. Bagby, E. L. Bockman, and J. J. Spitzer. 1980. Free fatty acid utilization by skeletal muscle after endotoxin administration. Am. J. Physiol. 239:391-395.

Rukkwamsuk, T. T., T. Wensing, and M. J. H. Geelen. 1998. Effect of overfeeding during the dry period on regulation of adipose tissue metabolism in dairy cows during the periparturient period. J. Dairy Sci. 81:2904-2911.

Steiger, M., M. Senn, G. Altreuther, D. Werling, F. Sutter, M. Kreuzer, and W. Langhans. 1999. Effect of a prolonged low-dose lipopolysaccharide infusion on feed intake and metabolism in heifers. J. Anim. Sci. 77:2523-2532.

Stone, W. C. 2004. Nutritional approaches to minimize subacute ruminal acidosis and laminitis in dairy cattle. J. Dairy Sci. 87(E Suppl.):E12-E26.

Van Soest, P. J., J. B. Robertson, and B. A. Lewis. 1991. Methods for dietary fiber, neutral detergent fiber and non-starch polysaccharide in relation to animal nutrition. J. Dairy Sci. 74:3583-3597.

Zebeli, Q., J. Dijkstra, M. Tafaj, H. Steingass, B. N. Ametaj, and W. Drochner. 2008a. Modeling the adequacy of dietary fiber in dairy cows based on the responses of ruminal $\mathrm{pH}$ and milk fat production to composition of the diet. J. Dairy Sci. 91:2046-2066.

Zebeli, Q., M. Tafaj, V. Ölschläger, B. Junck, B. N. Ametaj, and W. Drochner. 2008b. Evaluation of the response of ruminal fermentation and activities of non-starch polysaccharide-degrading enzymes to particle length of corn silage in dairy cows. J. Dairy Sci. 91:2388-2398.

Zenser, T. V., and M. C. Powanda. 1977. Effect of leukocytic endogenous mediators on endocrine pancreas secretor responses. Am. J. Physiol. 233:240-245. 